\title{
A NÃO FISCALIZAÇÃO DOS ÓRGÃOS GOVERNAMENTAIS E A TRAGÉDIA DA SAMARCO ${ }^{i}$
}

\section{THE ABSENCE OF FISCALIZATION OF THE GOVERNMENTAL AGENCIES AND THE SAMARCO TRAGEDY}

\author{
Carla Cristina Oliveira dos Santos ${ }^{\mathrm{ii}}$ \\ Diego Panázio Zeitune iii \\ João Luiz Mendonça dos Santos ${ }^{\text {iv }}$
}

\begin{abstract}
Resumo: Este estudo reflete a sistemática de fiscalização dos órgãos governamentais em relação às mineradoras, com vistas a avaliar a ineficiência de tais órgãos no que tange à tragédia acontecida no dia 05 de novembro de 2015 com o rompimento da estrutura da barragem de Fundão, da mineradora Samarco, quando cerca de sessenta e dois milhões de toneladas de lama, rejeitos de exploração de minério de ferro, destruíram completamente o distrito de Bento Rodrigues, em Mariana, afetando também muitas outras cidades. As conclusões indicam que existem importantes leis ambientais e órgãos para fiscalizar as mineradoras, mas que não funcionaram para impedir o referido desastre.
\end{abstract}

Palavras-Chave: Mineração. Samarco. Desastre. Leis ambientais. Fiscalização. Controle.

Abstract: In this study, we approached the system of supervision of government agencies in the face of the tragedy that occurred on November 5, 2015 in Minas

\footnotetext{
'Artigo publicado no livro "Dossiê Mariana: O Desastre Ambiental que o Brasil não pode esquecer" com o título "Tragédia da Samarco: Ausência de Controle e Fiscalização dos Órgãos Oficiais".

ii Possui Graduação em Direito pela Universidade Estácio de Sá (1998) e Graduação em Gestão em Recursos Humanos (2013), cursando Mestrado em Desenvolvimento Local (2016) na UNISUAM e cursando a Graduação em Administração (2014). Tenho Pós Graduação Latu Sensu em Direito do Trabalho e Direito Civil e Processo. Atualmente é Professora Adjunta da Universidade Estácio de Sá.

iii Mestre em Desenvolvimento Local, no Centro Universitário Augusto Motta (UNISUAM), especialista em Gestão Empresarial pelo Instituto $A$ Vez do Mestre e graduação em Administração e nível médio realizados no Centro Federal de Educação Tecnológica Celso Suckow da Fonseca (CEFET-RJ). Atua desde 2014 no Departamento de Recursos Humanos da Companhia de Pesquisa de Recursos Minerais, desenvolvendo ações referentes ao plano de carreiras, cargos e salários. Atua também nas atividades relativas ao concurso público, as transferências dos empregados e o Plano de Desligamento Incentivado e de Sucessão Programada (PDISP). Além disso, exerceu por dois anos a função de administrador do Centro Cultural e Esportivo Israelita Adolpho Bloch.

iv Mestre em Desenvolvimento Local pela Sociedade Unificada de Ensino Augusto Motta - UNISUAM (2017), Especialista em Direito de Família e Sucessões pela Universidade Cândido Mendes - UCAM (2016), Especialista em Engenharia Ambiental pela Universidade Castelo Branco - UCB (2014), Especialista em QSMS-R pela Universidade Castelo Branco - UCB (2013), Especialista em Educação Ambiental pelo Serviço Nacional de Aprendizagem Comercial - SENAC (2011), Graduação em Direito pelo Centro Universitário Moacyr Sreder Bastos - CUMSB (1999).
} 
Gerais. The disaster struck when the Samarco mining company broke the Fundão dam structure, when about sixty-two million tons of mud, tailings from iron ore mining, completely destroyed the Bento Rodrigues district in Mariana, also affecting many other cities. There are important environmental laws and agencies to oversee mining companies, but there is a lack of better management of public money for social and environmental purposes and the proper functioning of the control bodies.

Keywords: Mining. Samarco. Disaster. Environmental laws. Oversight. Control. 


\section{INTRODUÇÃO}

No Brasil, as leis que protegem o meio ambiente são várias e consideradas muito atuais, a começar pela Carta Magna de 1988, que em seu artigo 225 afirma que todos têm direito ao meio ambiente ecologicamente equilibrado, sendo este um bem de uso comum do povo e essencial à sadia qualidade de vida, impondo-se ao Poder Público e à coletividade do dever de defendê-lo e preservá-lo para as presentes e futuras gerações.

Também pelo que se verifica há muitos órgãos fiscalizadores, sobretudo no âmbito da mineração, sendo o Departamento Nacional de Produção Mineral, DNPM, o mais importantes em escala nacional. Tal órgão possui entre uma de suas finalidades a de controlar e fiscalizar as atividades de mineração em todo território nacional.

No âmbito estadual, há a Secretaria de Meio Ambiente e Desenvolvimento Sustentável (SEMAD), responsável pela conservação do meio Ambiente no estado de Minas Gerais e a Fundação do Meio Ambiente, que atua vinculada à SEMAD. Essa fundação é responsável pela denominada Agenda Marrom, cuja incumbência fundamental é o controle da degradação ambiental decorrente de atividades poluidoras.

O desastre em Mariana, em razão de suas dimensões, ocorreu após a estrutura da barragem de Fundão, que armazena resíduos da mineradora Samarco, se romper. Os rejeitos assolaram mais de 40 cidades da Região Leste de Minas Gerais, adentrou pelo Espírito Santo e foi considerado o maior desastre ambiental do Brasil, deixando 17 mortos, 2 pessoas desaparecidas, além de acabar com vidas animais e devastar cerca de 1469 hectares de vegetação. Houve perda de estruturas públicas e privadas, afetando também a diversidade marinha, a flora, a fauna terrestre, a interrupção da pesca, do turismo, além de interromper o abastecimento de água, prejudicando a geração de energia elétrica.

No caso de Bento Rodrigues, em apenas 12 minutos, todo o Distrito foi devastado pela enxurrada de lama. Esse material que inundou a região é composto por rejeitos sólidos e líquidos e as amostras afirmam que estão concentradas partículas de metais pesados como alumínio, chumbo, bário, ferro, boro, cobre e 
mercúrio, levados para o Rio Doce, um dos principais e mais importantes de Minas Gerais.

\section{LEIS AMBIENTAIS BRASILEIRAS}

Nos últimos 50 anos, o Brasil oficializou inúmeras normas de proteção e fiscalização do Meio Ambiente. Não obstante o número de leis e decretos, a tragédia anunciada da Samarco acabou acontecendo, deixando um rastro de destruição. A tabela a seguir mostra a abrangência do aparato legal do Brasil, traz o número da Lei, o ano de sanção e o tema que ela regula.

\section{Tabela 1 - Leis Ambientais}

\begin{tabular}{|c|c|c|}
\hline Norma & Ano de sanção & Tema que regula \\
\hline Lei 5.197 & $03 / 01 / 1967$ & Dispõe sobre a fauna. \\
\hline Lei $n^{\circ} 6.453$ & $17 / 10 / 1977$ & $\begin{array}{l}\text { Dispõe sobre a responsabilidade civil por danos } \\
\text { nucleares e a responsabilidade criminal por atos } \\
\text { relacionados com atividades nucleares e dá } \\
\text { outras providências. }\end{array}$ \\
\hline Lei $n^{\circ} 6.766$ & 19/12/1979 & $\begin{array}{l}\text { Dispõe sobre o parcelamento do solo urbano e } \\
\text { dá outras providências. }\end{array}$ \\
\hline Lei $n^{\circ} 6.803$ & $02 / 07 / 1980$ & $\begin{array}{l}\text { Dispõe sobre as diretrizes básicas para o } \\
\text { zoneamento industrial das áreas críticas de } \\
\text { poluição, e dá outras providências. }\end{array}$ \\
\hline Lei $n^{\circ} 6.902$ & 27/04/1981 & $\begin{array}{l}\text { Dispõe sobrea criação das Estações Ecológicas, } \\
\text { Áreas de Proteção Ambiental e dá outras } \\
\text { providências. }\end{array}$ \\
\hline Lei $n^{\circ} 6.938$ & $31 / 08 / 198$ & $\begin{array}{l}\text { Dispõe sobre a Política } \\
\text { Ambiente, seus fins e mecanal do Meio } \\
\text { formulação e aplicação, e dá outras } \\
\text { providências. }\end{array}$ \\
\hline Lei $n^{\circ} 7.347$ & $24 / 07 / 1985$ & $\begin{array}{l}\text { Disciplina a ação civil pública de } \\
\text { responsabilidade por danos causados ao meio } \\
\text { ambiente, ao consumidor, a bens e direitos de } \\
\text { valor artístico, estético, histórico, turístico e } \\
\text { paisagístico e dá outras providências. }\end{array}$ \\
\hline Lei $n^{\circ} 7.661$ & $16 / 05 / 1988$ & $\begin{array}{l}\text { Institui o Plano Nacional de Gerenciamento } \\
\text { Costeiro e dá outras providências. }\end{array}$ \\
\hline Lei n 7.735 & $22 / 02 / 1989$ & $\begin{array}{l}\text { Dispõe sobre a extinção de órgão e de entidade } \\
\text { autárquica, cria o Instituto Brasileiro de Meio } \\
\text { Ambiente e dos Recursos Naturais Renováveis } \\
\text { e dá outras providências. }\end{array}$ \\
\hline
\end{tabular}




\begin{tabular}{|c|c|c|}
\hline Lei $n^{0} 7.082$ & $11 / 07 / 1989$ & $\begin{array}{l}\text { Dispõe sobre a pesquisa, a experimentação, a } \\
\text { produção, a embalagem e rotulagem, o } \\
\text { transporte, o armazenamento, a } \\
\text { comercialização, a propaganda comercial, a } \\
\text { utilização, a importação, a exportação, o destino } \\
\text { final dos resíduos e embalagens, o registro, a } \\
\text { classificação, o controle, a inspeção e a } \\
\text { fiscalização de agrotóxicos, seus componentes } \\
\text { e afins, e dá outras providências. }\end{array}$ \\
\hline Lei n 7.085 & $18 / 07 / 1989$ & $\begin{array}{l}\text { Altera o decreto Lei } \mathrm{n}^{\circ} 227 \text {, de } 28 / 02 \text { de } 1967 \text {, } \\
\text { cria o regime de permissão de lavra garimpeira, } \\
\text { extingue o regime de matrícula, e dá outras } \\
\text { providências. }\end{array}$ \\
\hline Lei $n^{\circ} 8.171$ & $17 / 01 / 1991$ & Dispõe sobre a política agrícola. \\
\hline Lei $n^{\circ} 9.433$ & 08/01/1997 & $\begin{array}{l}\text { Institui a Politica Nacional de Recursos Hídricos, } \\
\text { cria o Sistema Nacional de Gerenciamento de } \\
\text { Recursos hídricos, regulamenta o inciso XIX do } \\
\text { art. } 21 \text { da Constituição Federal, e altera o art. } 1^{\circ} \\
\text { da Lei } n^{\circ} 8.001 \text {, de } 13 / 03 / 1990 \text {, que modificou a } \\
\text { Lei } n^{\circ} 7.990 \text {, de } 28 / 12 / 1989 \text {. }\end{array}$ \\
\hline Lei n 9.605 & $12 / 02 / 1998$ & $\begin{array}{l}\text { Dispõe sobre as sanções penais } \mathrm{e} \\
\text { administrativas derivadas de condutas } \\
\text { atividades lesivas ao meio ambiente, e dá outras } \\
\text { providências. }\end{array}$ \\
\hline Lei 9.795 & 27/04/1999 & $\begin{array}{l}\text { Dispõe sobre a educação ambiental, institui a } \\
\text { Política Nacional de Educação Ambiental, e dá } \\
\text { outras providências. }\end{array}$ \\
\hline $\begin{array}{ll}\text { Decreto } & n^{\circ} \\
3.179 & \end{array}$ & $21 / 09 / 1999$ & $\begin{array}{l}\text { Dispõe sobre a especificação das sanções } \\
\text { aplicáveis às condutas e atividades lesivas ao } \\
\text { meio ambiente, e dá outras providências. }\end{array}$ \\
\hline Lei 9.984 & $17 / 07 / 2000$ & $\begin{array}{l}\text { Dispõe sobre a criação da Agência Nacional das } \\
\text { Águas - ANA, entidade federal de } \\
\text { implementação da Política Nacional de } \\
\text { Recursos Hídricos e de coordenação do } \\
\text { Sistema Nacional de Gerenciamento de } \\
\text { Recursos Hídricos, e dá outras providências. }\end{array}$ \\
\hline Lei $n^{\circ} 12305$ & $02 / 08 / 2010$ & $\begin{array}{l}\text { Institui a Política Nacional de Resíduos Sólidos; } \\
\text { altera a Lei nº } 9.605 \text { de 12/02/1998, e dá outras } \\
\text { providências. }\end{array}$ \\
\hline Lei $\mathrm{n}^{\circ} 12.334$ & $20 / 09 / 2010$ & $\begin{array}{l}\text { Estabelece a Política Nacional de Segurança de } \\
\text { barragens destinadas a acumulação de água } \\
\text { para quaisquer usos, à disposição final ou } \\
\text { temporária de rejeitos e à acumulação de } \\
\text { resíduos industriais, cria o Sistema Nacional de } \\
\text { informações sobre Segurança de Barragens e } \\
\text { altera a redação do art. } 35 \text { da Lei } 9.433 \text { de } \\
08 / 01 / 1997 \text {, e do art. } 4^{\circ} \text { da Lei } 9.984 \text { de }\end{array}$ \\
\hline
\end{tabular}




\begin{tabular}{|c|c|c|}
\hline & & 17/07/2000. \\
\hline Lei $\mathrm{n}^{\circ} 12.608$ & $10 / 04 / 2012$ & $\begin{array}{l}\text { Institui a Política Nacional de Proteção e Defesa } \\
\text { Civil, PNPDEC; dispõe sobre o Sistema } \\
\text { Nacional de Proteção e Defesa Civil - SINPDEC } \\
\text { e o Conselho Nacional de Proteção e Defesa } \\
\text { Civil - CONPDEC; autoriza a criação de } \\
\text { sistemas de informações e monitoramento de } \\
\text { desastres; altera as Leis nos } 12.340 \text {, de } 10 \text { de } \\
\text { dezembro de 2010, } 10.257 \text {, de } 10 \text { de julho de } \\
2001 \text {, } 6.766 \text {, de } 19 \text { de dezembro de } 1979 \text {, } \\
\text { 8.239, de } 4 \text { de outubro de } 1991 \text {, e } 9.394 \text {, de } 20 \\
\text { de dezembro de } 1996 \text {; e dá outras providências. }\end{array}$ \\
\hline
\end{tabular}

Fonte: Elaborada pelos autores.

Dados contidos na página oficial do Ministério do Meio Ambiente (2016) afirmam que a Política Nacional de Resíduos Sólidos, PNRS, instituída pela Lei 12.305/10, contém instrumentos importantes, que permitem ao país avançar e combater os principais problemas ambientais e socioeconômicos, que decorrem do manejo inadequado dos resíduos sólidos, uma vez que foram criados o Sistema de Informações sobre a Gestão dos Resíduos Sólidos, SINIR, e os Planos de Resíduos Sólidos, PRS.

O SINIR tem como objetivo armazenar, tratar e fornecer informações que apoiem as funções ou processos de uma organização. Essencialmente é composto de um subsistema formado por pessoas, processos, informações e documentos, e outro composto por equipamentos e seus meios de comunicação. Já o PRS contem metas e estratégias nacionais sobre o tema. Também estão previstos planos estaduais, microrregionais, de regiões metropolitanas, planos intermunicipais, municipais de gestão integrada de resíduos sólidos e os planos de gerenciamento de resíduos sólidos.

Não só a Lei 12.305, que institui a Política Nacional de Resíduos Sólidos, PNRS, mas também a Lei $n^{\circ} 12.334$, que estabelece a Política Nacional de Segurança de Barragens destinadas a acumulação de água para quaisquer usos, deixam as pessoas mais impactadas diante do desastre da mineradora Samarco, o que resta claro que não bastam boas legislações para proteger o meio ambiente da ação de empresas gananciosas que só visam ao lucro. 


\section{A FISCALIZAÇÃO DO DNPM PODERIA TER EVITADO A TRAGÉDIA?}

Há uma pergunta muito importante que todos fazem: Essa tragédia provocada pela Samarco poderia ter sido evitada? Ao proferi-la, começa-se a buscar os responsáveis, além, obviamente, da empresa Samarco, um dos principais personagens apontados é o Departamento Nacional de Produção Mineral (DNPM). Segundo informações de seu site oficial trata-se de uma autarquia federal, criada pela Lei 8.876/1994, vinculado Ministério de Minas e Energia, dotado de personalidade jurídica de direito público, com autonomia patrimonial, administrativa e financeira, com sede e foro em Brasília, com circunscrição em todo Território Nacional.

Esse órgão tem por finalidade promover o planejamento e fomento da exploração mineral e do aproveitamento dos recursos minerais e superintender as pesquisas geológicas, minerais, e de tecnologia mineral, bem como assegurar, controlar e fiscalizar o exercício das atividades de mineração em todo o território nacional, na forma do que dispõem o Código de Mineração, o Código de Águas Minerais, os respectivos regulamentos e a legislação que complementa. Sua missão é gerir o patrimônio mineral brasileiro, de forma social, ambiental e economicamente sustentável, utilizando instrumentos de regulação em benefício da sociedade e sua visão é de ser reconhecido como uma instituição de excelência capaz de gerir o patrimônio mineral de forma sustentável no interesse da nação.

Ele é legalmente responsável pela fiscalização das barragens de rejeitos (art.5, III), através da Portaria $n^{\circ} 416$, de 03 de setembro de 2012, que institui o Cadastro Nacional de Barragens de Mineração, que estabelece a estrutura e conteúdo mínimo do plano de segurança a ser elaborado pelo empreendedor. Além disso, delega ao empreendedor as inspeções regulares, que deverá enviar ao departamento.

Cabe mencionar, a partir de dados da ONG Contas Abertas (2015), que o DNPM, apesar de tamanha responsabilidade, após cortes orçamentários do governo federal, em 2015, ficou com dificuldade de realizar suas funções fiscalizadoras, uma que recebeu do governo federal para programas de fiscalização das atividades minerárias apenas 1,3 milhões de reais, o que corresponde a apenas $13,2 \%$ do que 
estava previsto na Lei Orçamentária. No ano de 2014, os repasses foram mais de 3,6 milhões de reais.

Dados do Ministério de Minas e Energia (2015) afirmam que somente após o incidente em Mariana, o governo acelerou para liberar $\mathrm{R} \$ 9$ milhões de reais, para a realização de medidas de emergência, principalmente no que diz respeito à contratação de auditoria independente com expertise para avaliar barragens e também contratar novos geólogos.

Merece registro a alegação do DNPM de que a falta de pessoal é também um empecilho que prejudica a qualidade do serviço prestado pelo setor. O órgão conta com cerca de 990 funcionários, sendo apenas 220 técnicos responsáveis por verificar as 662 barragens cadastradas, metade delas em Minas Gerais. O país tem 30,9 mil títulos de lavra, 29 mil títulos de pesquisa e conta com poucos funcionários para essa atividade em todo extenso território nacional. No ano de 2014, por exemplo, apenas 34\% das barragens foram fiscalizadas (MNE, 2015).

Pimenta de Ávila, engenheiro geotécnico e especialista em barragens de rejeitos, pontua que seria necessário multiplicar o quadro efetivo atual do DNPM por dez para se fazer uma fiscalização bem feita, bem documentada e bem transparente para a sociedade brasileira (GONÇALVES; FUSCO, VESPA, 2015).

Importante frisar que a situação agravou mais ainda, sete meses após o desastre, pois após sofrer novos cortes, o órgão se viu obrigado a dispensar funcionários terceirizados, em Minas Gerais, o que atrapalha a fiscalização das barragens de minérios do Estado, incluindo o andamento do estudo sobre a realidade de cada uma das estruturas do solo mineiro (AGOSTINO, 2015). Apesar desses demitidos não atuarem com atividades de fiscalização, eles se dedicavam aos trabalhos mais burocráticos, que foram repassados para os geólogos e engenheiros do departamento. De acordo com o ouvidor do DNPM, Paulo Santana, essas demissões foram inevitáveis após o contingenciamento da verba (cerca de 60\%) (AGOSTINO, 2015).

A falta de pessoal, em sintonia com publicação da revista Época (2015) impediu o DNPM de fazer a fiscalização in loco, aceitando e acreditando nos relatórios que as empresas enviam como foi o caso da Samarco. Falta até gasolina na autarquia para que os fiscais cheguem às barragens. $O$ não comparecimento 
frequente dos fiscais pode ser considerado uma falha gravíssima no processo de fiscalização, como no caso da barragem do Fundão, os técnicos do governo federal ficou sem vistoriar as barragens e acompanhar sua estrutura por 3 anos. A última vez que o DNPM havia visitado a área atingida foi em 2012. Após essa visita houve inúmeras mudanças significativas na estrutura, como alteamento, sem qualquer tipo de monitoramento. (CORREA; LIMA; GOMIDE, 2015).

\section{A ATUAÇÃO DA SECRETARIA DE MEIO AMBIENTE (MG) E DA FUNDAÇÃO ESTADUAL DO AMBIENTE PODERIA TER EVITADO A TRAGÉDIA?}

Faz-se uma nova pergunta: a atuação da Secretaria de Meio Ambiente (MG) e da Fundação Estadual do Ambiente (MG) poderia ter evitado a tragédia? A resposta é que sim. A secretaria de Meio Ambiente e Desenvolvimento Sustentável (SEMAD) tem como missão formular e coordenar a política estadual de proteção e conservação do meio ambiente e de gerenciamento de recursos hídricos e articular as políticas da gestão dos recursos ambientais, visando ao desenvolvimento sustentável do estado de Minas Gerais. O Sistema Estadual de Meio Ambiente e Recursos Hídricos é formado pela Secretaria de Estado de Meio Ambiente e Desenvolvimento Sustentável (SEMAD), pelos Conselhos Estaduais de Política Ambiental (COPAM) e de Recursos Hídricos (CERH) e pelos órgãos vinculados: Fundação Estadual de Meio Ambiente (FEAM), responsável pela qualidade ambiental no estado, no que concerne a Agenda Marrom, Instituto Estadual de Florestas (IEF), responsável pela agenda Verde e Instituto Mineiro de Gestão das Águas (IGAM), que responde pela agência Azul. Importante frisar que a agenda Marrom é relacionada à prevenção e controle da degradação ambiental decorrente de atividades poluidoras, e pelo desempenho de atividades correlatas, como a realização de estudos e pesquisas sobre poluição, qualidade do ar, da água e do solo. (SEMAD, 2016)

Estão nas competências da SEMAD planejar, propor e coordenar a gestão ambiental integrada no Estado, com vistas à manutenção dos ecossistemas e do desenvolvimento sustentável; consolidar, em conjunto com órgãos e entidades que atuam na área ambiental, normas técnicas a serem por eles observadas, 
coordenando as ações pertinentes; promover a aplicação da legislação e das normas especificas de meio ambiente e recurso naturais; coordenar e supervisionar as ações voltadas para a proteção ambiental; garantir a execução da política ambiental e de gestão de recursos hídricos do Estado; desenvolver atividades informativas e educativas, relacionadas aos problemas ambientais; estabelecer a cooperação técnica, financeira e institucional com organismos internacionais e estrangeiros, visando a proteção ambiental e ao desenvolvimento sustentável do estado.

Quanto à fiscalização, o SEMAD possui uma Superintendência de Fiscalização Ambiental Integrada e quatro diretorias, que são: Estratégia em Fiscalização, de Recursos Hídricos e Atmosféricos e do Solo, de Recursos Florestais e de Pesca.

O problema é que, consoante dados publicados pela Revista Época (2015), assim como o DNPM, a SEMAD sofre com a falta de estrutura e de profissionais para exercer suas atividades. Há apenas oito fiscais para fiscalizar 735 barragens. $O$ órgão vem sofrendo inúmeras críticas, pois em 2013, quando a Samarco solicitou novo licenciamento para a barragem do Fundão, um laudo técnico do Instituto Prístino, encomendado pelo Ministério Público de Minas Gerais, apontou um risco de "colapso de estrutura" e, mesmo assim, a licença foi concedida pela Secretaria de Meio Ambiente de Minas Gerais. (CORREA; LIMA; GOMIDE, 2015).

Já a Fundação Estadual do Meio Ambiente, FEAM, órgão seccional de apoio ao Conselho Estadual de Política Ambiental (COPAM, 2016), atua vinculada à SEMAD e tem por finalidade executar a política de proteção, conservação e melhoria da qualidade ambiental, no que concerne a gestão do ar, do solo e dos resíduos sólidos, bem como a prevenção e a correção da poluição ou da degradação ambiental, provocada pelas atividades industriais, minerárias e de infraestrutura, promover e realizar ações, projetos e programas de pesquisa para o desenvolvimento de tecnologias ambientais, e apoiar tecnicamente as instituições do Sistema Estadual de Meio Ambiente, SISEMA, visando a preservação e à melhoria da qualidade ambiental do Estado de Minas Gerais.

Importante notar que entre as incumbências da FEAM está o inventário de resíduos sólidos minerários, em que os responsáveis por empreendimentos de 
mineração devem apresentar ao órgão, anualmente, até o dia 31 de março, o inventário de resíduos sólidos referentes ao ano civil anterior, de acordo com a deliberação normativa COPAM 117/2008. O envio dos inventários das fontes geradoras de resíduos minerários permite a elaboração do inventário Estadual de resíduos sólidos minerários.

Ora, no Brasil, a descentralização é regida por Lei. Os órgãos ambientais dos estados e municípios podem efetuar licenciamento e fiscalização, amparados na (Lei complementar 140/2011), no caro da Barragem de Fundão, a Fundação Estadual do Meio Ambiente de Minas Gerais (FEAM/MG) é o órgão fiscalizador e licenciador, que deveria ter tomado as medidas previstas na legislação em relação à Samarco. Logo, a atuação da SEMAD e de sua Fundação poderia ter impedido, ou pelo menos minimizado os impactos do desastre.

\section{A RESPONSABILIDADE DA SAMARCO}

Não obstante a ineficácia da fiscalização e controle dos órgãos estatais brasileiros, a Política Nacional de Segurança de Barragens é clara ao consignar que o empreendedor é o responsável legal pela segurança da barragem, cabendo-lhe o desenvolvimento de ações para garantir sua estabilidade. Conforme essa mesma legislação, a fiscalização da segurança das estruturas cabe à entidade que outorga direito de mineração, que no caso é o DNPM.

Ora, a mineradora Samarco afirmou em seu site oficial, no dia 06 de nov. de 2015, um dia após o desastre, que todas as suas barragens "possuem licenças de operação concedidas pela Superintendência Regional de Regularização Ambiental, órgão que, nos recorrentes processos de fiscalização, atesta o comportamento e a integridade das estruturas".

A empresa alegou que a última fiscalização ocorreu em julho de 2015 e indicou que as suas estruturas se encontravam em totais condições de segurança. Afirmou também que realiza inspeções próprias, conforme a Lei Federal de Segurança de Barragens, e conta com uma equipe de operação 24 horas por dia para manutenção e identificação, de forma imediata, de qualquer anormalidade. 
Inclusive, o DNPM chegou a considerar como "de baixo risco" tendo como base em auditorias realizadas pela própria mineradora.

Apesar dessas alegações, é fato que não havia por parte da Samarco nenhum plano de contingência, com o propósito de responder à gestão de risco e segurança da barragem (o que foi reconhecido implicitamente pela mineradora), muito embora a empresa tenha procurado minimizar seus atos, através dos comunicados "Samarco informa".

A falta de um sistema de alarmes sonoros para informar aos trabalhadores e moradores potencialmente afetados contraria a Convenção 176 e à Recomendação da Organização Internacional do Trabalho (OIT) sobre Segurança e Saúde nas Minas, adotadas em Genebra, em 22 de junho de 1995, pela 85a Sessão da Conferência Internacional do Trabalho e promulgada pelo Brasil pelo Decreto 6.270 de 22 de novembro de 2007.

Anderson Pires, professor de engenharia, que já analisou 125 barragens em Minas Gerais, afirma que era impossível a Samarco não saber o que estava prestes a acontecer, pois uma barragem não se rompe de um dia para o outro. Dá avisos, dá sinais. O que gera dúvida é se havia, ou não, monitoramento para captar esses sinais. Ele fez a comparação de como uma pessoa adoece: percebem-se os sintomas. (CORREA; LIMA; GOMIDE, 2015).

Sandra Cureau, subprocuradora-geral da República e coordenadora da Câmara do Meio Ambiente do Ministério Público Federal, argumenta que a punição dos representantes da Samarco deve ser "exemplar", por ter havido omissão e negligência. Ela disse que desde maio de 2015 duas empresas faziam obras para a Samarco de elevação da altura da barragem, chamado de alteamento. Ela cobra a responsabilidade pelos danos causados pela empresa, que deve indenizar as vitimas e responder pelos crimes cometidos, pois não deve ser o povo brasileiro, através dos seus impostos, que deve pagar pelo que a Samarco fez. (CORREA; LIMA; GOMIDE, 2015).

A aplicabilidade da pena à pessoa jurídica que comete crime ambiental está descrita no artigo 21 da lei 9.605/98, que prevê a aplicação da pena das seguintes formas: isolada, alternativa ou cumulativa, podendo ainda ocorrer: multa, restrição de direitos e de prestação de serviços à comunidade, sendo sua variação avaliação 
de acordo com o caso. O artigo 18 da lei prevê que a pena de multa terá o seu cálculo dentro dos critérios do Código Penal e sua proporcionalidade calculada ao valor da vantagem econômica auferida e à capacidade econômica do infrator, podendo ser estipulada de três vezes até o mesmo que aplicada em seu valor máximo.

O artigo 54 da mesma lei estabelece que, ocasionar poluição de natureza diversa e em níveis que possam causar dano à saúde humana, ou provoque morte de animais, bem como destruição significativa da flora é passível de pena de um a quatro anos, e multa. Também em seu segundo parágrafo, estabelece como crime: a) Tornar uma área, urbana ou rural, imprópria para a ocupação humana; b) Causar poluição atmosférica que provoque a retirada, ainda que momentânea, dos habitantes das áreas afetadas, ou que cause danos diretos à saúde da população; c) Causar poluição hídrica que torne necessária a interrupção do abastecimento público de água de uma comunidade; d) Dificultar ou impedir o uso público das praias; e) Ocorrer por lançamento de resíduos sólidos, líquidos ou gasosos, ou detritos, óleos ou substâncias oleosas, em desacordo com as exigências estabelecidas em leis ou regulamentos; a pena será ainda maior resultando em reclusão, de um a cinco anos.

A lei 6.938 , de $31 / 08 / 1981$, em seu artigo 14 , parágrafo $1^{\circ}$, também reforça que o poluidor é "obrigado, independente da existência de culpa, a indenizar ou reparar os danos causados ao meio ambiente e a terceiros, afetados por sua atividade".

Após a tragédia, comissões permanentes da Câmara Federal reuniram representantes do governo, de órgãos de fiscalização e do Ministério Público, que apontaram, com unanimidade, a culpa da empresa pelo desastre ambiental. Para calcular os valores da indenização, o procurador José Adércio Sampaio, escolheu um caso emblemático que pudesse servir de comparação e a opção se deu pela explosão da plataforma Deepwater Horizon, da empresa petrolífera British Petroleum, em 2010, no Golfo do México. No episódio, 11 pessoas morreram e cerca de 4,9 milhões de barris de óleo vazaram para o mar. O procurador afirmou, com base em estudos preliminares, que se pode concluir que os impactos humanos, econômicos e socioambientais da tragédia de Mariana são, no mínimo, equivalentes 
àqueles verificados no Golfo do México. Em 2014, a British Petroleum, em laudo divulgado em seu site, reconheceu os danos no valor de US\$43,8 bilhões que, convertidos em reais, daria os R\$155 bilhões (RODRIGUES, 2016).

Nos EUA, o órgão máximo de fiscalização de barragens é a Federal Emergency Management Agency. Os governos dos estados ficam responsabilizados por $95 \%$ das barragens do país, mas cabe a FEMA liderar os seus fiscais, através do Programa Nacional de Segurança em Barragens, que tem como objetivo garantir que os Estados tenham condições, treinamento, desenvolvimento e recursos para monitoramento de acidentes com barragens. Cada Estado, por sua vez, deve cumprir as regras e diretrizes definidas no programa nacional. Uma dessas atividades é compilar em um banco de dados na Universidade Stanford, na Califórnia, todos os incidentes nas quase 80 (oitenta) mil barragens do país. (CORREA; LIMA; GOMIDE, 2015).

Já o Canadá não possui agências de fiscalização, mas as províncias monitoram suas barragens com muita seriedade e rigor. A Austrália iniciou o processo de regulação de segurança de barragens em 1978 e no ano de 2.000 o seu governo aprovou um código que prevê que toda barragem tenha relatórios anual de segurança e um programa de fiscalização elaborado por um engenheiro de segurança. Ainda mais cedo, em 1930, o Reino Unido já regulava suas barragens, elaborando seu conjunto de leis. Estas foram aperfeiçoadas em 1975 e estão em vigência até os dias de hoje. A lei obriga que dois técnicos escolhidos façam a medição diária do nível dos reservatórios e produzam um relatório por ano. (CORREA; LIMA; GOMIDE, 2015).

Pelos dados, verifica-se que os países centrais, no aspecto da responsabilidade, são muito mais eficazes e rigorosos com a fiscalização. Empresas estrangeiras não fazem nesses países citados o que fazem no Brasil.

Mônica Zuffo, doutora em segurança de barragens pela Unicamp, entrevistada pela revista Época (2015), alerta que a falta de exigência legal para o uso de métodos mais modernos de aviso, como sirenes e envio de mensagens pelo telefone celular para comunicar, caso haja algum risco de acidente, é muito comum em outros países. A função primordial da regulamentação é determinar uma harmonização dos procedimentos. A legislação brasileira peca ao não definir ou 
especificar quem deve fiscalizar. É observado qual órgão é responsável por fiscalizar, mas não define uma instância máxima no processo fiscalizatório, subentendendo que os incidentes nas barragens brasileiras são ocasionados por fenômenos naturais.

Há de se definir requisitos mínimos de segurança, uniformizar os critérios empregados na sua avaliação, permitir uma supervisão consistente, da segurança de barragens, de modo a conduzir à execução de melhorias, que contribuam para o aumento da segurança dessas estruturas.

\section{CONSIDERAÇÕES FINAIS}

Em virtude da paralisação das atividades da Samarco após a tragédia, segundo dados da prefeitura de Mariana, o município deixa de arrecadar cerca de 9 milhões por mês só com impostos sobre circulação de mercadorias (ICMS) e valores relevantes referentes ao imposto sobre serviços e da compensação financeira pela exploração de recursos minerais (CFem), fazendo com que isso comprometa suas finanças. (AGOSTINO, 2015).

Não obstante a importância macro e microeconômica da mineradora Samarco para a região de Mariana e para o Brasil fica evidenciado, após o percurso desse estudo, que aqueles que exploram recursos minerais - que muitos acreditam que o lucro deveriam ser de todos os brasileiros e não de grupos internacionais são obrigados a recuperar o meio ambiente degradado, de acordo com a solução técnica exigida pelos órgãos competentes e que as condutas e atividades consideradas prejudiciais ao meio ambiente precisam ser punidas, independente de pessoas físicas ou jurídicas, sanções penais e administrativas, independentemente da obrigação de reparar os danos causados.

Infelizmente, as atitudes realizadas pelos órgãos competentes geralmente são tomadas apenas após as grandes tragédias, como a de Mariana. Muitos estudiosos e juristas pugnam por um novo Código de Mineração, para substituir um regulamento que vigora desde 1967 e se encontra totalmente defasado, mas não adianta mudar uma lei, ou melhorá-la se os governantes do Brasil não mudarem a sua postura ética em relação ao trato da coisa pública. Leis e órgãos para fiscalizar 
e controlar as mineradoras os brasileiros tem. O que falta é melhor gerenciamento do dinheiro público e funcionamento das instituições existentes.

É fato cristalino que o Poder Público Federal e do Estado de Minas Gerais sempre demonstraram um descaso em relação a essa tragédia, escondendo suas responsabilidades e não expondo de maneira clara o que foi efetivamente realizado quanto as suas fiscalizações.

Importante registrar que o Governo Federal editou o Decreto $\mathrm{n}^{\circ} 8.572$, no dia 13 de novembro de 2015, alterando o artigo $2^{\circ}$ do Decreto 5.113 , de 22 de junho de 2004, incluindo como natural o desastre decorrente do rompimento ou colapso de barragens que ocasione movimento de massa, com danos a unidades residenciais, com a intenção de possibilitar que a população afetada pudesse sacar o FGTS. Atitude que se analisada amplamente põe em dúvida as responsabilidades do governo federal, do Estado de Minas Gerais e da Samarco.

Sabe-se que a defesa do meio ambiente entra constantemente em atrito com os exploradores que almejam o lucro fácil. Em razão disso, as leis ambientais precisam ser acionadas contra as empresas que causam impactos ambientais, como as que produzem resíduos poluentes. Em 1984, Carlos Drummond de Andrade, considerado por muitos como o poeta mais influente do Brasil, já discutia o assunto, em seu poema Lira Itabirana:

\author{
O Rio é Doce \\ A Vale? Amarga. \\ $\mathrm{Ai}$, antes fosse \\ Mais leve a carga. \\ Entre estatais \\ E multinacionais, \\ Quantos ais! \\ A dívida interna, \\ A dívida externa, \\ A dívida eterna. \\ Quantas toneladas exportamos \\ De ferro? \\ Quantas lágrimas disfarçamos \\ Sem berro?
}




\section{REFERÊNCIAS}

AGOSTINO, Rosane. Rompimento de barragem em Mariana: perguntas e respostas. G1 Globo.com, São Paulo, 13 nov. 2015. Ciência e Saúde. Disponível em: <http://g1.globo.com/ciencia-e-saude/noticia/2015/11/rompimento-de-barragensem-mariana-perguntas-e-respostas.html>. Acesso em: 25 jul. 2016.

ARPINI, N. Polícia Federal lista falhas da Samarco com barragem rompida. G1 ES tvGazeta. 22 jun. 2016. Desastre ambiental no Rio Doce. Disponível em: <http://g1.globo.com/espirito-santo/desastre-ambiental-no-riodoce/noticia/2016/06/pf-lista-falhas-que-levaram-barragem-da-samarcoromper.html>. Acesso em: 23 jul. 2016.

ANDRADE, C. Lira Itabirana. Jornal Cometa. Minas Gerais. 1984.

BRASIL. Constituição (1988). Disponível em:

<http://www.planalto.gov.br/ccivil_03/constituicao/constituicao.htm>. Acesso: 30 jul. 2016.

Decreto $\mathrm{n}^{\circ}$ 3.179, de 21 de setembro de 1999. Disponível em:

$\overline{<h t t p: / / w w w 2 . c a m a r a . l e g . b r / l e g i n / f e d / d e c r e t / 1999 / d e c r e t o-3179-21-s e t e m b r o-1999-~}$ 344968-norma-pe.html>. Acesso em: 13 jul. 2016.

Departamento Nacional de Produção Mineral (DNPM). Disponível em: <http://www.dnpm.gov.br/>. Acesso em: 27 jul. 2016.

Empresa Brasileira de Comunicação (EBC). Disponível em: <http://www.ebc.com.br/>. Acesso em: 27 jul. 2016.

Lei complementar $\mathrm{n}^{\circ} 140$, de 8 de dezembro de 2011. Disponível em: <http://www.planalto.gov.br/ccivil_03/leis/LCP/Lcp140.htm>. Acesso em: 20 jul. 2016.

Lei 5.197, de 03 de janeiro de 1967. Disponível em:

<http://www.planalto.gov.br/ccivil_03/leis/L5197.htm>. Acesso em: 20 jul. 2016.

Lei $n^{\circ}$ 6.453, de 17 de outubro de 1977. Disponível em:

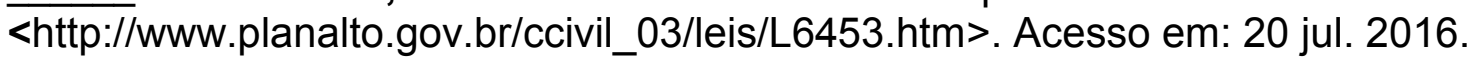

Lei $\mathbf{n}^{\circ}$ 6.766, de 19 de dezembro de 1979. Disponível em:

<http://www.planalto.gov.br/ccivil_03/leis/L6766.htm>. Acesso em: 20 jul. 2016.

Lei $\mathbf{n}^{\circ} \mathbf{6 . 8 0 3}$, de 02 de julho de 1980. Disponível em:

<http://www.planalto.gov.br/ccivil_03/leis/L6803.htm>. Acesso em: 20 jul. 2016.

Lei $n^{\circ}$ 6.902, de 27 de março de 1981. Disponível em:

<http://www.planalto.gov.br/ccivil_03/leis/L6902.htm>. Acesso em: 20 jul. 2016. 
Lei $\mathbf{n}^{\circ}$ 6.938, de 31 de agosto de 1981. Disponível em:

<http://www.planalto.gov.br/ccivil_03/leis/L6938.htm>. Acesso em: 20 jul. 2016.

Lei $\mathbf{n}^{\circ}$ 7.347, de 24 de julho de 1985. Disponível em:

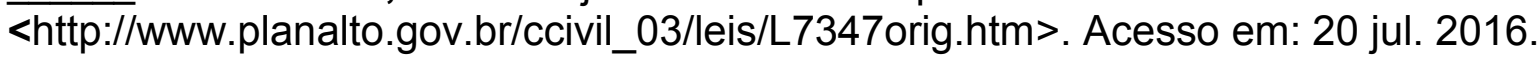

Lei $\mathbf{n}^{\circ}$ 7.661, de 16 de maio de 1988. Disponível em:

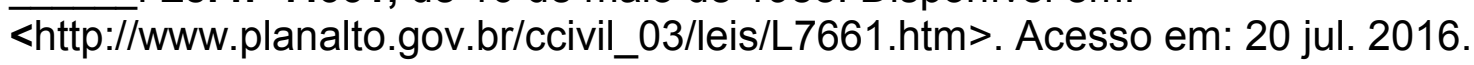

Lei $\mathbf{n}^{\circ}$ 7.735, de 22 de fevereiro de 1989. Disponível em:

<http://www.planalto.gov.br/ccivil_03/leis/L7735.htm>. Acesso em: 20 jul. 2016.

Lei $\mathbf{n}^{\circ}$ 7.082, de 11 de julho de 1989. Disponível em:



Lei $\mathbf{n}^{\circ}$ 7.085, de 18 de julho de 1989. Disponível em:

<http://www.planalto.gov.br/ccivil_03/leis/L9314.htm>. Acesso em: 20 jul. 2016.

Lei $\mathbf{n}^{\circ}$ 8.171, de 17 de janeiro de 1991. Disponível em:

<http://www.planalto.gov.br/ccivil_03/leis/L8171.htm>. Acesso em: 20 jul. 2016.

Lei $\mathbf{n}^{\circ}$ 9.433, de 08 de janeiro de 1997. Disponível em:

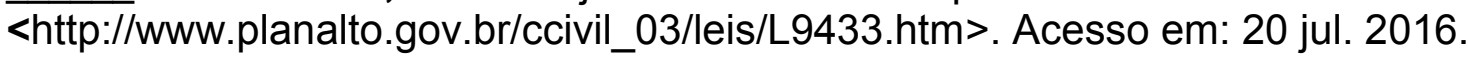

Lei $\mathbf{n}^{\circ}$ 9.605, de 12 de fevereiro de 1998. Disponível em:

<http://www.planalto.gov.br/ccivil_03/leis/L9605.htm>. Acesso em: 20 jul. 2016.

Lei 9.795, de 27 de março de 1999. Disponível em:

<http://www.mma.gov.br/port/conama/legiabre.cfm?codlegi=321>. Acesso em: 20 jul. 2016.

Lei 9.984, de 17 de julho de 2000. Disponível em:

<http://www.mma.gov.br/port/conama/legiabre.cfm?codlegi=371>. Acesso em: 20 jul. 2016.

Lei $\mathbf{n}^{0}$ 12.305, de 02 de agosto de 2010. Disponível em:

<http://www.mma.gov.br/port/conama/legiabre.cfm?codlegi=636>. Acesso em: 20 jul. 2016.

Lei $\mathbf{n}^{0}$ 12.334, de 20 de setembro de 2010. Disponível em:

<http://www.planalto.gov.br/ccivil_03/_ato2007-2010/2010/lei/l12334.htm>. Acesso em: 20 jul. 2016.

Lei $\mathbf{n}^{\circ}$ 12.608, de 10 de março de 2012. Disponível em:

<http://www.planalto.gov.br/ccivil_03/_ato2011-2014/2012/lei/l12608.htm>. Acesso em: 20 jul. 2016. 
Manual de Segurança de Barragens. Brasília: Ministério da Integração Nacional, 2002. Disponível em: <http://www.mi.gov.br/seguranca-e-inspecao-debarragens>. Acesso em: 20 jul. 2016.

Ministério de Minas e Energia. 2015. Disponível em:

<http://www.mme.gov.br>. Acesso em: 20 jul. 2016.

Ministério do Meio Ambiente. 2016. Disponível em:

<http://www.mma.gov.br>. Acesso em: 20 jul. 2016.

Instituto Brasileiro de Geografia e Estatística (IBGE). Disponível em:

<http://www.ibge.gov.br/>. Acesso em: 20 jul. 2015.

CORREA, H; LIMA, S; GOMIDE, R. Mariana: os dramas e as culpas pela tragédia. Época, 20 nov. 2015. Disponível em:

$<$ http://epoca.globo.com/tempo/noticia/2015/11/mariana-os-dramas-e-culpas-pelatragedia.html>. Acesso em: 23 jul. 2016.

GONÇALVES, E; FUSCO, N; VESPA, T. Tragédia em Mariana. Para que não se repita. Veja, 18 nov. 2015. Disponível em:

$<$ http://veja.abril.com.br/complemento/brasil/para-que-nao-se-repita/>. Acesso em: 25 jul. 2016

JORNAL O TEMPO. Publicado em 02 jul. 2016. Disponível em:

<http://www.otempo.com.br/cidades/com-equipe-j\%C3\%A1-enxuta-dnpm-demite-81dos-terceirizados-1.1312092>. Acesso em: 27 jul. 2016.

LEVANTAMENTOS da ONG Contas Abertas. 12 nov. 2015. Disponível em: <http://www.contasabertas.com.br/website/arquivos/12175>. Acesso em: 20 jul. 2016.

MINAS GERAIS. Fundação Estadual do Meio Ambiente (FEAM). Disponível em: <http://www.feam.br/instituicao>. Acesso em: 27 jul. 2016.

MINAS GERAIS. Secretaria de Estado de Meio Ambiente e Desenvolvimento Sustentável (SEMAD). Disponível em: <http://www.meioambiente.mg.gov.br>. Acesso em: 27 jul. 2016.

MINAS GERAIS. Conselho Estadual de Política Ambiental, COPAM, Disponível em: <http://www.meioambiente.mg.gov.br/copam>. Acesso em: 25 jul. 2016.

RODRIGUES, Léo. MPF cobra R 155 bi para reparar danos do rompimento da barragem da SAMARCO. Agência Brasileira de Comunicação, Belo Horizonte, 03 mai. 2016. Disponível em: <http://agenciabrasil.ebc.com.br/geral/noticia/201605/mpf-cobra-r-155-bi-para-reparar-danos-do-rompimento-da-barragem-dasamarco>. Acesso em: 15 jun. 2016. 
SAMARCO. Publicação de 06 nov. 2015. Disponível em:

<http://www.samarco.com/2015/11/06/comunicado-2-2/ . Acesso em: 20 jul. 2016. 